\title{
Sulfur transfer and activation by ubiquitin-like modifier system Uba4•Urm1 link protein urmylation and tRNA thiolation in yeast
}

\author{
André Jüdes ${ }^{1}$, Alexander Bruch ${ }^{1}$, Roland Klassen ${ }^{1}$, Mark Helm ${ }^{2}$ and Raffael Schaffrath ${ }^{1, *}$ \\ ${ }^{1}$ Universität Kassel, Institut für Biologie, FG Mikrobiologie, Heinrich-Plett-Str. 40, 34132 Kassel, Germany. \\ ${ }^{2}$ Johannes Gutenberg Universität Mainz, Institut für Pharmazie und Biochemie, Staudinger Weg 5, 55128 Mainz, Germany. \\ * Corresponding Author: \\ Raffael Schaffrath, Universität Kassel, Institut für Biologie, FG Mikrobiologie, Heinrich-Plett-Str. 40; 34132 Kassel, Germany; Tel: +49 \\ 561804 4175; Fax: +49 561804 4337; E-mail: schaffrath@uni-kassel.de
}

\begin{abstract}
Urm1 is a unique dual-function member of the ubiquitin protein family and conserved from yeast to man. It acts both as a protein modifier in ubiquitin-like urmylation and as a sulfur donor for tRNA thiolation, which in concert with the Elongator pathway forms 5-methoxy-carbonyl-methyl-2-thio $\left(\mathrm{mcm}^{5} \mathrm{~s}^{2}\right)$ modified wobble uridines (U34) in anticodons. Using Saccharomyces cerevisiae as a model to study a relationship between these two functions, we examined whether cultivation temperature and sulfur supply previously implicated in the tRNA thiolation branch of the URM1 pathway also contribute to proper urmylation. Monitoring Urm1 conjugation, we found urmylation of the peroxiredoxin Ahp1 is suppressed either at elevated cultivation temperatures or under sulfur starvation. In line with this, mutants with sulfur transfer defects that are linked to enzymes (Tum1, Uba4) required for Urm1 activation by thiocarboxylation (Urm1-COSH) were found to maintain drastically reduced levels of Ahp1 urmylation and $\mathrm{mcm}^{5} \mathrm{~s}^{2} \mathrm{U} 34$ modification. Moreover, as revealed by site specific mutagenesis, the Stransfer rhodanese domain (RHD) in the E1-like activator (Uba4) crucial for Urm1-COSH formation is critical but not essential for protein urmylation and tRNA thiolation. In sum, sulfur supply, transfer and activation chemically link protein urmylation and tRNA thiolation. These are features that distinguish the ubiquitin-like modifier system Uba4•Urm1 from canonical ubiquitin family members and will help elucidate whether, in addition to their mechanistic links, the protein and tRNA modification branches of the URM1 pathway may also relate in function to one another.
\end{abstract}

doi: $10.15698 /$ mic2016.11.539

Received originally: 13.09.2016;

in revised form: 19.09.2016,

Accepted 19.09.2016,

Published 24.10.2016.

Keywords: Saccharomyces cerevisiae, ubiquitin-like modifier Urm1, protein urmylation, tRNA thiolation, E1-like enzyme Uba4, sulfur transferase Tum1, tRNase zymocin.

\section{INTRODUCTION}

In eukaryotes, the activity of many diverse proteins can be modulated by conjugation to ubiquitin and ubiquitin-like modifiers [1, 2]. Among the latter, Urm1 from Saccharomyces cerevisiae [3] is unique since it can act as a lysine-directed protein modifier in ubiquitin-like urmylation and as a sulfur donor for tRNA anticodon thiolation [4-9]. Both roles are exchangeable among eukaryotes $[10,11]$ and based on dual-function Urm1-like proteins in archaea and bacteria [12, 13], conserved Urm1 systems appear to be important in all domains of life. In line with this, their inactivation triggers stress-induced growth defects in microbes, organ underdevelopment in plants and, strikingly, lethality in flies $[3,4,8,12-17]$.
In contrast to ATP-dependent ubiquitin adenylation and conjugation by E1-E3 enzymes, E2/E3 activities for Urm1 are unknown, and Urm1 activation by its E1-like enzyme Uba4 results in C-terminal thiocarboxylation (Urm1COSH) $[18,19]$. This is similar to E1-like (MoeB or ThiF) activation of bacterial S-carrier proteins (MoaD or ThiS) that donate sulfur for molybdopterin or thiamine synthesis rather than being involved in protein conjugation $[20,21]$. So in addition to eukaryal ubiquitin-like proteins, Urm1 relates to prokaryal S-carriers [19]. In line with this, a conserved S-relay system contributes to Urm1-COSH formation (Fig. 1). It starts with desulfurase Nfs1 that mobilizes sulfur from cysteine for direct S-transfer onto Uba4 (Fig. 1) or indirectly via sulfur transferase Tum1 [7-10]. Uba4 is 
composed of MoeB-like (see above) and rhodanese-type domains (MoeBD, RHD) that carry thiol-active cysteines [3, $8,18,22]$. S-transfer to the one in RHD results in a persulfide (Fig. 1) which following adenylation of Urm1 by the MoeBD forms an acyl-disulfide with the modifier [18, 21]. Upon reductive cleavage of this bond, Urm1-COSH gets released $[18,23]$ to donate the activated sulfur species for S-insertion into tRNAs (Fig. 1) by thiolase (Ncs2•Ncs6) [7-9].

In concert with the conserved Elongator pathway, this generates 5-methoxy-carbonyl-methyl-2-thio $\left(\mathrm{mcm}^{5} \mathrm{~s}^{2}\right)$ modifications of wobble uridines (U34) in tRNA anticodons [24-26]. These support codon-anticodon interaction for efficient mRNA decoding [27], which explains why $\mathrm{mcm}^{5} \mathrm{~s}^{2} \mathrm{U} 34$ modification defects in Elongator and URM1 pathway mutants cause translational defects such as frameshift errors, tRNA anti-suppression and ribosomal stalling [28-30]. Evidence demonstrating that tRNA modifications including $\mathrm{mcm}^{5} \mathrm{~s}^{2} \mathrm{U} 34$ can change in response to environmental cues suggests dynamics in their formation $[31,32]$. Whether this is due to active regulation is an attractive option that is supported by recent data showing that Elongator and thiolase proteins undergo posttranslational modifications including reversible phosphorylation and intriguingly, urmylation itself [6, 14, 33-36].

As for its urmylation role, data obtained under steadystate-conditions suggest the major pool of non-conjugated Urm1 is in its thiocarboxylate form [6, 37]. So Urm1-COSH formation by Uba4 (Fig. 1) per se seems not to be sufficient for conjugation. However, when exposed to the thiol oxi- dizer diamide, Urm1-COSH generated in vitro becomes engageable in urmylation [6]. Together with evidence that reactive oxygen species (ROS) and diamide induce urmylation in yeast and human cells, the S-carrier and protein modifier functions of Urm 1 were proposed to be coupled to each other linking both to oxidative stress $[4,6,11,37]$. In support of this is the evidence showing that ROS detoxifying peroxiredoxins are urmylated in yeast (Ahp1) and fruit flies (Prx5) [4, 6, 11, 17].

Because of its dual-functionality Urm1 was coined a ubiquitin-like fossil at the crossroad of S-transfer and protein conjugation [8], thus deviating from canonical ubiquitination which is not known to depend on sulfur supply, Stransferases or E1 enzymes with RHD domains. To better understand the functional diversification of an ancestral Scarrier into today's members of the ubiquitin family, we therefore studied whether Urm 1 dual-functions may be interlinked by comparing both tRNA thiolation and urmylation under URM1 pathway inactivating conditions $[36,38]$. Here we show that similar to heat-induced tRNA thiolation defects, Ahp1 urmylation in yeast is suppressed at $39^{\circ} \mathrm{C}$. Moreover, as is the case with tRNA thiolation, Ahp1 urmylation is highly responsive to sulfur availability and requires the S-relay system that is dedicated for proper tRNA thiolation (via Urm1-COSH formation). In line with this, Urm1 functions in tRNA thiolation and urmylation depend on the rhodanese-type S-transfer region RHD in Uba4 (crucial for Urm1-COSH formation). In sum, the two URM1 pathway branches, tRNA thiolation and protein

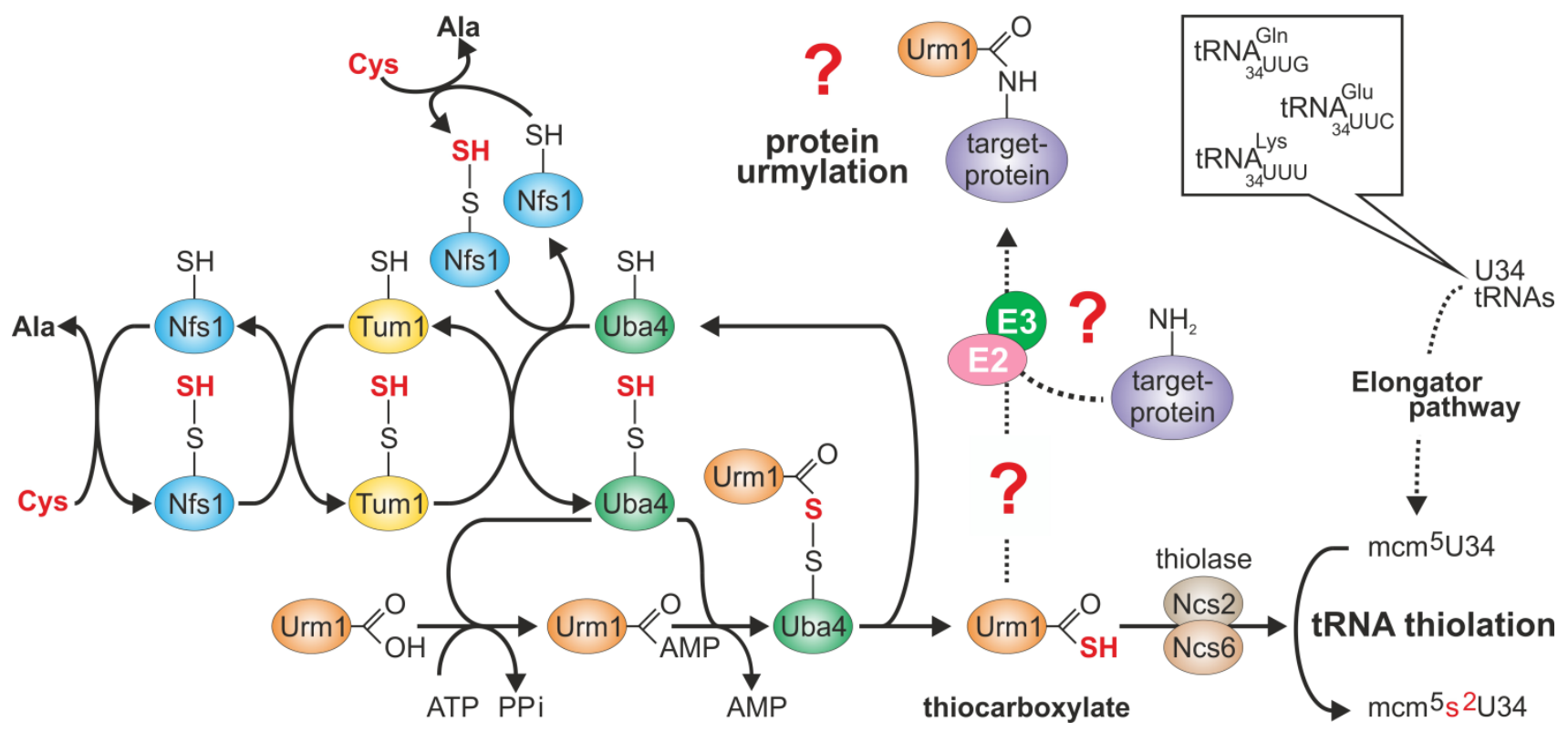

FIGURE 1: Sulfur flow within the URM1 pathway. The scheme depicts sulfur (red) flow and URM1 pathway players required for mobilization (Nfs1), transfer (Tum1), activation (Uba4, Urm1) or consumption (Ncs2•Ncs6) of sulfur. E1-like activator Uba4 (green) is key to Urm1 thiocarboxylation. Urm1-COSH formed this way donates sulfur to the tRNA thiolation branch which cooperates with the Elongator pathway to form 5-methoxy-carbonyl-methyl-2-thio-uridine in wobble positions ( $\mathrm{mcm}^{5} \mathrm{~s}^{2} \mathrm{U} 34$ ) of the indicated tRNA anticodons. Possibly (?) Urm1COSH also feeds into the urmylation branch of the URM1 pathway. As for the latter, E2/E3 enzymes are elusive (?) and the relevance of urmylation for target protein function is ill-defined (?). The model is up-dated from work in the labs of Hayashi [7] and Suzuki [9]. 
urmylation, are chemically linked through sulfur supply, transfer and activation by the ubiquitin-like modifier system Uba4•Urm1.

\section{RESULTS}

Protein urmylation and tRNA thiolation are both thermosensitive

Loss of tRNA thiolation causes heat-sensitive growth in URM1 pathway mutants [7-9] and recently, URM1 pathway inactivation at $37^{\circ} \mathrm{C}$ or $39^{\circ} \mathrm{C}$ was shown to trigger tRNA thiolation defects sufficient for growth inhibition [36, 3941]. Hence, we studied the ability of Urm 1 to engage in urmylation at temperatures restrictive for tRNA thiolation. To do so, we used a yeast strain that expresses a TAPtagged Urm1 fusion ( $35 \mathrm{kDa}$ ) previously shown to conjugate to proteins such as Ahp1 and Uba4 [11]. TAP-URM1 cells were grown to logarithmic growth phase at $30^{\circ} \mathrm{C}$ and split into two cultures. One was kept at $30^{\circ} \mathrm{C}$, the other shifted to $39^{\circ} \mathrm{C}$ and both cultivated for three hours prior to protein urmylation analysis. Using electrophoretic mobility shift assays (EMSA) based on anti-TAP Western blots [11], we detected at $30^{\circ} \mathrm{C}$ non-conjugated TAP-Urm1 ( $\left.35 \mathrm{kDa}\right)$ and a prominent up-shifted ( $\sim 55 \mathrm{kDa}$ ) TAP signal (Fig. $2 \mathrm{~A}$ ). We confirmed this is an Ahp1•TAP-Urm 1 conjugate [11] by showing that it did not form in ahp1D mutants (Fig. 2A) and that it was further up-shifted when tagged in AHP1-c-myc cells (Fig. S1). At $39^{\circ} \mathrm{C}$, however, formation of Ahp1•TAPUrm1 conjugates gradually declined over time and was almost absent after three hours (Fig. 2A). Similarly, but less pronounced, the abundance of free TAP-Urm1 decreased over time, which contrasts with stable forms of unconjugated Ahp1 at $39^{\circ} \mathrm{C}$ (Fig. 2A). Our data thus indicate that rather than correlating with an unstable target, loss of Ahp1 urmylation at $39^{\circ} \mathrm{C}$ is likely due to a fragile Urm1 modifier itself.

tRNA thiolation and translation defects in URM1 pathway mutants cause phenotypes that can be rescued by overexpressing tRNAs normally undergoing $\mathrm{mcm}^{5} \mathrm{~s}^{2} \mathrm{U} 34$ modifications [8, 15, 25, 42, 43]. When higher-than-normal levels of these tRNAs, i.e. tRNA ${ }^{\text {Gln }}$, tRNA ${ }^{\text {Lys }}$ and tRNA ${ }^{\text {Glu }}$ [tQKE], were produced from a multi-copy plasmid, they failed to suppress either the Ahp1 urmylation defects or the low Urm 1 abundance at $39^{\circ} \mathrm{C}$ (Fig. 2B). This suggests it is not a translational defect suppressible by tRNAs which underlies heat-sensitive urmylation. In support of this, we observed that translation inhibition by cycloheximide had no effect on Urm1 levels (Fig. S2). With previous data showing proteins required for S-transfer (Tum1) and Urm1 activation (Uba4) are unstable, too [36, 38, 39], heatsensitivity of the URM1 pathway may thus be multifactorial In sum, Urm1 instability alone or combined with S-transfer defects at $39^{\circ} \mathrm{C}$ appear to inactivate urmylation and as previously shown, tRNA thiolation.

\section{Sulfur supply and activation link tRNA thiolation and} urmylation

Under conditions of methionine starvation, sulfur consuming pathways including $\mathrm{mcm}^{5} \mathrm{~s}^{2} \mathrm{U} 34$ modifications, which
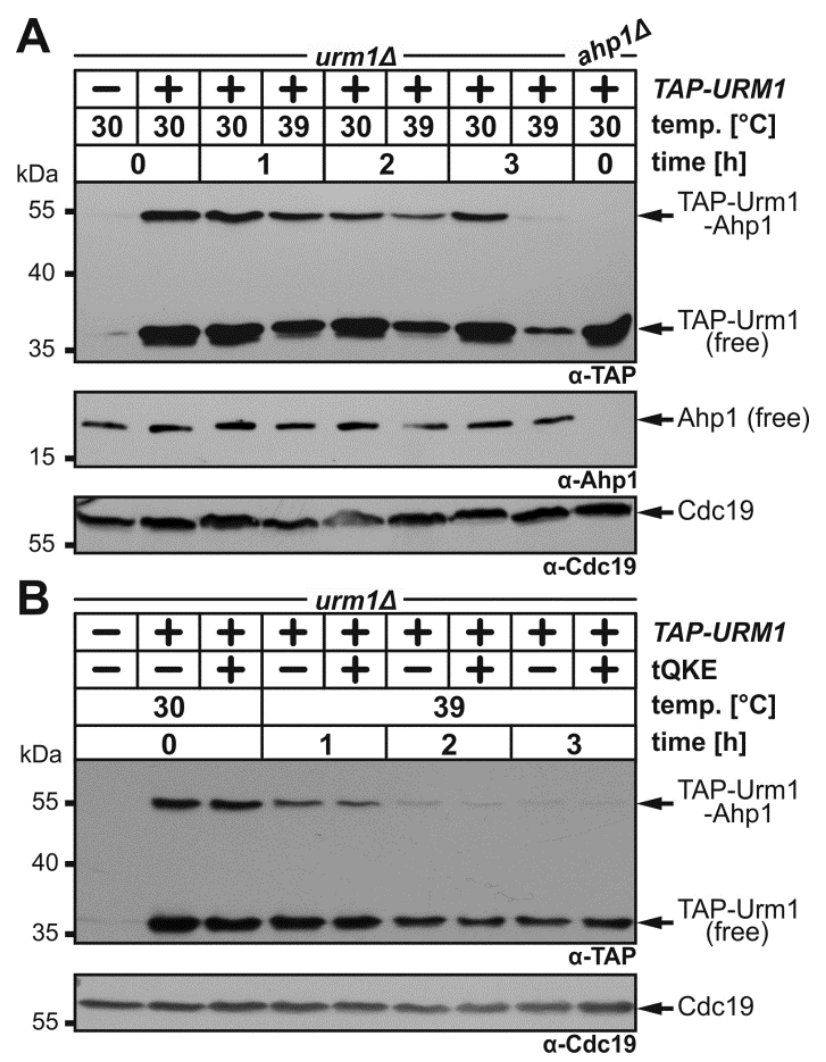

FIGURE 2: Overexpression of tRNAs subject to Urm1-dependent U34 thiolation fails to suppress loss of Ahp1 urmylation at $39^{\circ} \mathrm{C}$. (A) Urmylation of Ahp1 is suppressed at $39^{\circ} \mathrm{C}$. An urm $1 \Delta$ strain expressing TAP-URM1 was grown to logarithmic growth phase and split into two cultures prior to cultivation at $30^{\circ} \mathrm{C}$ or $39^{\circ} \mathrm{C}$ for three hours (h). Ahp1 urmylation analysis involved anti-TAP-based EMSA and immune blots with anti-Ahp1 to detect non-conjugated (free) Ahp1. Protein loading was controlled with anti-Cdc19 antibodies. (B) tRNA ${ }^{\text {Gln }}$, tRNA ${ }^{\text {Lys }}$ and tRNA ${ }^{\text {Glu }}$ (tQKE) overexpression cannot rescue defective Ahp1 urmylation at $39^{\circ} \mathrm{C}$. Except for tQKE overexpression from multi-copy vector pQKE (Table S3), cell growth at $30^{\circ} \mathrm{C}$ or $39^{\circ} \mathrm{C}$ and urmylation analysis were as described in $(A)$. Arrows $(A, B)$ indicate the positions of non-conjugated (free) forms of TAP-Urm1 and Ahp1, as well as TAP-Urm1 conjugated to Ahp1 and loading control Cdc19.

require Urm1, Elongator and S-adenosyl-L-methionine, have been shown to dramatically decline in yeast [38]. This reinforces that sulfur supply and activation in form of Urm1-COSH is critical for tRNA thiolation [7-9]. Hence, we compared sulfur dependency between the two URM1 pathway branches, i.e. protein urmylation and tRNA thiolation, by examining the effects of starvation for the sulfur amino acid methionine (Met). TAP-URM1 cells were shifted from Met-containing to Met-free media, and urmylation was analyzed by EMSA. In the presence of Met, we detected free TAP-Urm 1 and the prominent Ahp1 conjugate ( $\sim 55$ kDa) (Fig. 3A). Interestingly, while free TAP-Urm1 and nonconjugated Ahp1 remained stable irrespective of sulfur supply, urmylation of Ahp1 by TAP-Urm1 dramatically declined during S-starvation (Fig. 3A). Thus sulfur depletion 
specifically suppresses Urm1 conjugation indicating that by analogy with tRNA thiolation, protein urmylation is also sensitive to sulfur supply.

To study whether the sulfur relay system implicated in the S-donor role of Urm1 for tRNA thiolation [7-9] also contributes to urmylation, we compared both URM1 pathway branches in mutants with appropriate genetic defects (Fig. 3B, C). Here, loss of Urm1 activator Uba4 abolished Ahp1 urmylation in uba $4 \Delta$ cells (Fig. $3 \mathrm{C}$ ) which is consistent with LC-MS/MS analysis showing loss of $\mathrm{mcm}^{5} \mathrm{~s}^{2} \mathrm{U} 34$ modifications and increased $\mathrm{mcm}^{5} \mathrm{U} 34$ levels in tRNAs due to unaltered Elongator activity (Fig. 3B) [24, 38, 43]. While thiolase-minus $n \operatorname{cs} 6 \Delta$ cells produced U34 profiles similar to uba $4 \Delta$ (Fig. 3B), both $n \operatorname{cs} 2 \Delta$ and $n \operatorname{cs} 6 \Delta$ mutants maintained wild-type Ahp1 urmylation levels (Fig. $3 \mathrm{C}$ ). This agrees with previous data showing urmylation occurs in the absence of tRNA thiolation $[4,5]$. These read-outs contrast sharply with those of tum $1 \Delta$ cells lacking S-transferase Tum1 [22, 45]. As revealed by LC-MS/MS and EMSA, they are significantly reduced in tRNA thiolation and Ahp1 urmylation (Fig. $3 B, C)$. Indeed $\mathrm{mcm}^{5} \mathrm{~s}^{2} \mathrm{U} 34$ modifications in tum $1 \Delta$ cells declined to $\sim 16 \%$ of wild-type levels (Fig. 3B) indicating that S-transfer via Tum1 is critical for proper tRNA thiolation and Ahp1 urmylation.

EMSA exposed for longer times (Fig. S3) showed urmylation of proteins other than Ahp1 is also affected in tum $1 \Delta$ cells stressing the importance of S-transfer for Urm1 conjugation. Recently, yeast Uba4 and its human homolog (hUBA4/MOCS3) have been reported to undergo urmylation themselves $[6,11]$, so we studied Uba4 urmylation in a tum $1 \Delta$ strain that co-expressed c-Myc-tagged Uba4 and HA-marked Urm1. EMSA based on immune blots with anti-HA- and anti-c-Myc-antibodies allowed detection of Uba4•Urm1 conjugates ( $130 \mathrm{kDa}$ doublet band) (Fig. S4). Intriguingly, Uba4 urmylation was not sensitive to TUM1 deletion (Fig. S4) and disruption of NCS2, NCS6 or AHP1 also had no effect on Urm1 conjugation to Uba4. To sum up, our data show that protein urmylation (except for Uba4) depends on sulfur supply and on the sulfur relay system (Nfs1, Tum1, Uba4) that contributes to the S-donor role for Urm1 in tRNA thiolation. Hence, S-transfer and Urm1 thiocarboxylation apparently link tRNA thiolation and urmylation to each other.

\section{tRNA thiolation and urmylation are linked by catalytic Cys} residues in Uba4

Uba4 maintains two domains (MoeBD; RHD) with catalytic cysteines (C225; C397) (Fig. 4A). This organisation is peculiar since no E1 or other E1-like enzyme carries rhodaneselike domains (RHD) typical of S-transfer proteins such as Tum1 $[21,45]$. Since sulfur transfer to Uba4 via Tum1 is critical for Urm1 activation, we revisited C225 and C397 and examined their contributions to tRNA thiolation and urmylation. Previously, loss of function phenotypes were ascribed to cysteine ablative alanine (C225A or C397A) mutations and some of these were reported to lead to unstable proteins $[3,6,8,9,18]$.

Here, we generated single and double cysteine mimicking serine substitutions (C225S, C397S, C225S/C397S) that in striking contrast to the ablative ones differentially affected Uba4 functionality (Fig. 4). Using LC-MS/MS to compare thiolated $\left(\mathrm{mcm}^{5} \mathrm{~s}^{2} \mathrm{U} 34\right)$ and non-thiolated $\left(\mathrm{mcm}^{5} \mathrm{U} 34\right)$ tRNA modifications between UBA4 wild-type and uba4 $\triangle$ cells, we reconfirmed (Fig. $3 B$ ) loss of U34 thiolation and

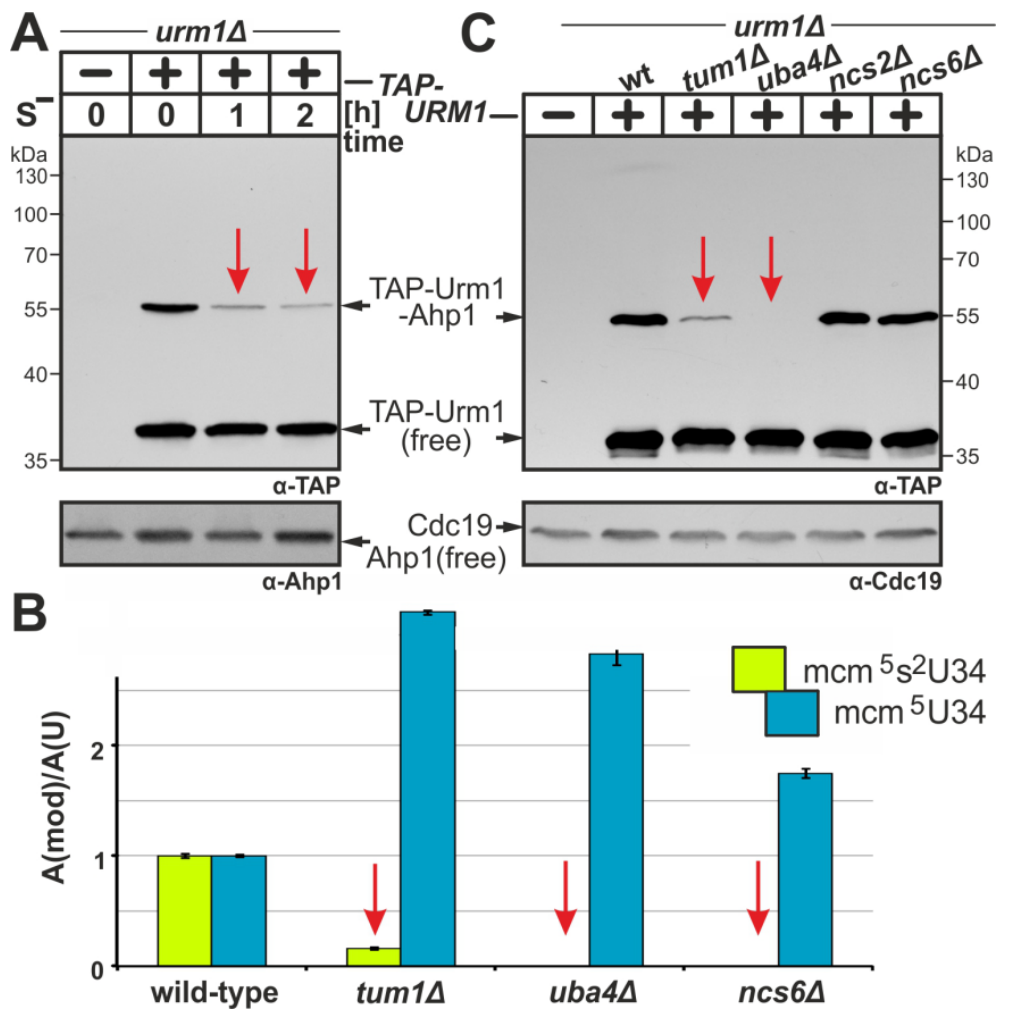

FIGURE 3: Sulfur supply, transfer and activation are critical for the tRNA thiolation and urmylation branches of the URM1 pathway. (A) Urmylation is sulfur sensitive. TAP-URM1 expressing cells (see Fig. 2) were grown in Met containing media prior to $S$ starvation ( $\mathrm{S}^{-}$) for two hours ( $\mathrm{h}$ ) in media without Met. Analysis of Ahp1 urmylation was as described (see Fig. 2). (B) LC-MS/MS-based tRNA (thio)modification analysis of modified U34 nucleoside content in tRNAs from wild-type and indicated URM1 pathway mutants. In each case, the modified nucleoside signal was normalized using total uridine content to allow comparison of the different samples. Inset: $\mathrm{mcm}^{5}$ (blue) and $\mathrm{mcm}^{5} \mathrm{~s}^{2}$ (green) modifications at U34. (C) Urmylation of Ahp1 is normal in thiolase-minus (ncs $2 \Delta, n \operatorname{cs} 6 \Delta$ ) cells but drastically reduced in the absence of S-transferase Tum1 (tum $1 \triangle$ ). Protein extracts from TAP-URM1 expressors of the indicated backgrounds (i.e. wild-type (wt) and URM1 pathway mutants) were subjected to Ahp1 urmylation assays as described (see Fig. 2). Non-conjugated (free) forms of TAP-Urm1 and Ahp1 as well as TAP-Urm1 conjugated to Ahp1 and loading control Cdc19 are indicated by arrows $(A, C)$. 
mcm ${ }^{5} 34$ accumulation in the latter background (Fig. 4B). This agrees with previous data showing Uba4 is essential for tRNA thiolation [7, 9, 25, 38, 43]. Intriguingly, rather than eliminating Uba4 function, C225S or C397S partially restored U34 thiolation in uba4A cells with $\mathrm{mcm}^{5} \mathrm{~s}^{2} \mathrm{U} 34$ levels (25\%: C225S; 23\%: C397S) significantly reduced compared to wild-type (100\%: UBA4) (Fig. 4B). Also, LC$\mathrm{MS} / \mathrm{MS}$ revealed $\mathrm{mcm}^{5} \mathrm{~s}^{2} \mathrm{U} 34$ formation became further reduced in the double mutant (14\%: C225S/C397S) (Fig. $4 \mathrm{~B})$ meaning that in combination, the two substitutions are additive and synthetically enhance the tRNA thiolation defects of the single mutants alone.

To prove these $\mathrm{mcm}^{5} \mathrm{~s}^{2} \mathrm{U} 34$ defects are phenotypically relevant, we introduced the Cys substitutions into uba4 $\Delta$ reporter cells with no functional Elongator (elp3 $\Delta$ ) or Deg1 $(\operatorname{deg} 1 \Delta)$. In addition to loss of U34 thiolation, both reporter strains lack other tRNA modifications: Elp3 (as part of Elongator) cooperates with Uba4•Urm 1 in $\mathrm{mcm}^{5} \mathrm{~s}^{2} \mathrm{U} 34$ formation and Deg1 is necessary for pseudouridine synthesis at tRNA positions 38 and $39[46,47]$. The combined tRNA modifications defects in the two reporter strains result in thermosensitive growth that can be rescued by tRNA overexpression implying the phenotype is due to improper tRNA function $[41,43,44]$. Hence, suppression of thermosensitivity by Uba4 rescues the consequences of the tRNA thiolation defects (Fig. S5). Using this assay diagnostic for tRNA thiolation, we found that while C225S and C397S alone partially rescued thermosensitive growth of the elp $3 \Delta u b a 4 \Delta$ and $\operatorname{deg} 1 \Delta u b a 4 \Delta$ reporter strains, the double

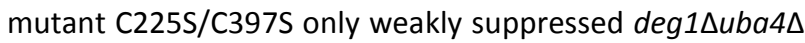
cells (Fig. S5). So, C225S, C397S and C225S/C397S progressively reduce the capacity of Uba4 to restore growth and tRNA thiolation, a notion congruent with their differential U34 modification profiles (Fig. 4B).

Using EMSA we next compared urmylation in the Cys substitution mutants to wild-type and found the single ones (C225S, C397S) were clearly reduced in TAPUrm1•Ahp1 conjugate formation (Fig. 4C). Again, in the C225S/C397S double mutant, defective urmylation was even further aggravated compared to each mutant alone but, importantly, not entirely abolished (Fig. 4C). Together, these urmylation assays go hand-in-hand with the tRNA thiolation profiles (Fig. 4B) and indicate that the Cys residues in the MoeBD (C225) and RHD (C397) regions of Uba4 overlap in function and collectively, contribute to full Uba4 functionality for proper tRNA thiolation and urmylation.

\section{The rhodanese domain (RHD) in Uba4 links tRNA thiola- tion and urmylation}

Having shown above that S-transfer is critical for Urm1 activation by $\mathrm{Uba} 4$ and that thiol-active cysteines are important to do so, we next focused on the role of the RHD, a rhodanese-like region in Uba4 with sulfur acceptor activity $[18,23]$. Upon RHD removal from Uba4 (Fig. 5A), we examined the ability of the resulting truncation $\left(\mathrm{Uba}_{1-328}\right)$ to mediate tRNA thiolation and urmylation in uba4A cells. LC$\mathrm{MS} / \mathrm{MS}$ analysis showed that $\mathrm{mcm}^{5} \mathrm{~s}^{2} \mathrm{U} 34$ modifications in tRNA anticodons from UBA4 ${ }_{1-328}$ cells dramatically declined down to $\sim 4 \%$ of UBA4 wild-type levels (Fig. 5B). Markedly,
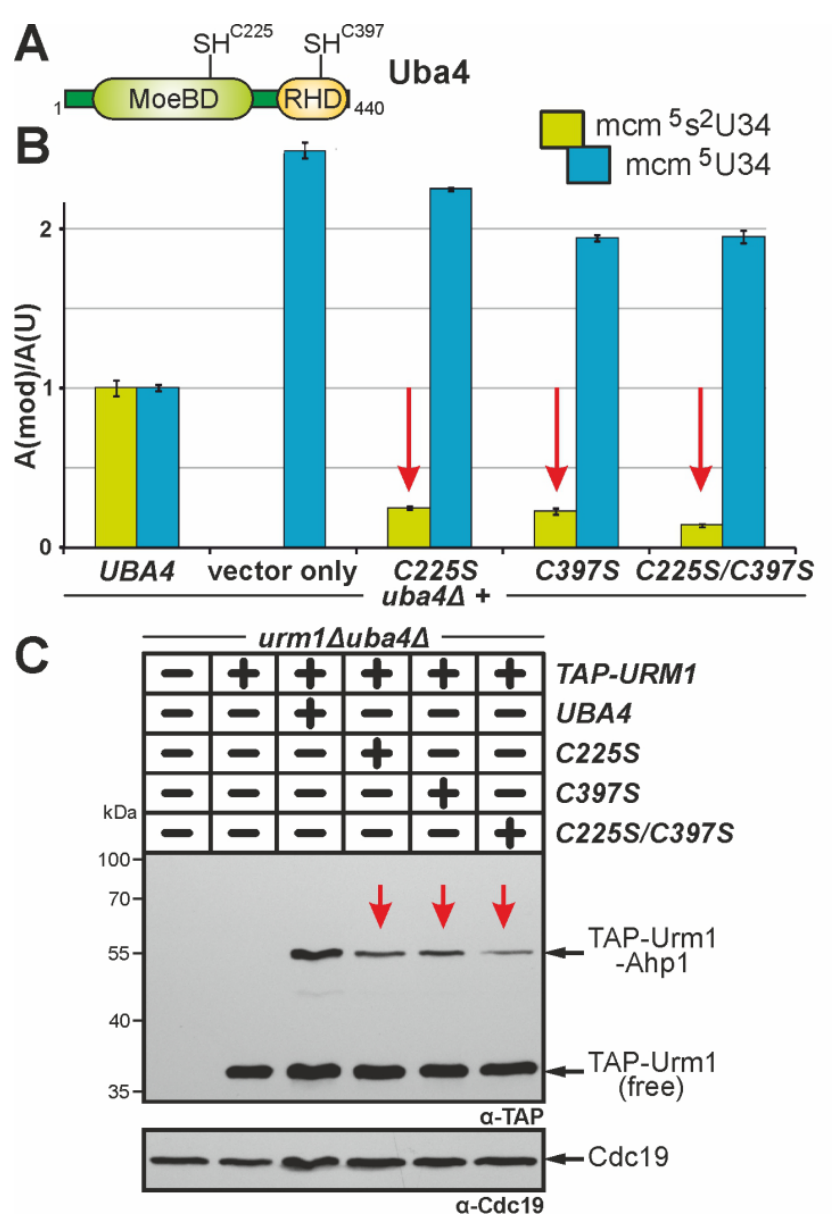

FIGURE 4: Cys225 and Cys397 are critical but not essential for Uba4 to activate Urm1 functions in tRNA thiolation and urmylation. (A) Uba4 scheme depicting MoeBD and RHD regions and the positions of Cys225 and Cys397. (B) tRNA (thio)modification analysis via LC-MS/MS (see Fig. 3) reveals Cys225 and/or Cys397 substitution mutants significantly interfere (red arrows) with formation of the mcm $\mathrm{s}^{2} \mathrm{U} 34$ modification. (C) Ahp1 urmylation is strongly (red arrows) affected by the C225S, C397S and C225S/C397S mutants. Urmylation assays (see Fig. 2) involved anti-TAP-based EMSA to detect non-conjugated (free) TAP-Urm1 and TAP-Urm1•Ahp1 conjugates. Protein loading was controlled with anti-Cdc19 antibodies.

these very low residual thiolation levels still partially suppressed the thermosensitive growth of the elp3 $\Delta u b a 4 \Delta$ and $\operatorname{deg} 1 \Delta u b a 4 \Delta$ reporter strains (Fig. S6). Thus, even without an RHD, $\mathrm{Uba}_{1-328}$ apparently engages in residual Urm1 activation sufficient enough for low-level tRNA thiolation. Indeed, this notion also correlates with EMSA showing that urmylation including Urm1 conjugation to Ahp1 was drastically affected in $U B A 4_{1-328}$ cells with low-level of Ahp1 $\bullet$ TAP-Urm1 conjugates detectable after longer exposure times (Fig. 5C). Thus, our results identify the RHD region on Uba4 as the main contributor to Urm1 dualfunctions in TRNA thiolation and urmylation.

When we tried to rescue $U B A 4_{1-328}$ cells by coexpressing $U B A 4_{329-440}$ (encoding the RHD alone), we were 
not able to improve tRNA thiolation based on its failure to rescue deg1 $1 \Delta$ uba $4 \Delta$ cell growth and suppress Urm1 conjugation defects (Fig. S7). Together with our observation that $U B A 4_{329-440}$ alone could not rescue defective tRNA thiolation or urmylation (Fig. S7) in $u b a 4 \Delta$ cells, our data suggest that in order to enable Urm1 activation and thiocarboxylation, both Uba4 domains (MoeBD \& RHD) need to be maintained in close proximity or on the same polypeptide rather than being provided separately. In sum, our results show that although catalytically critical for Uba4, the RHD on its own is non-functional. Probably, this explains why the MoeBD alone in Uba4 ${ }_{1-328}$ has residual E1like activity sufficient for very low-level tRNA thiolation and urmylation.

\section{Tum1 feeds into tRNA thiolation and urmylation through the RHD in Uba4}

Our data above indicate tRNA thiolation and urmylation defects in tum $1 \Delta$ cells correlate with reduced S-transfer to Uba4 and improper Urm1 thiocarboxylation. Hence, we asked whether loss of TUM1 would affect low-level tRNA thiolation and urmylation observed in the absence of the RHD (Uba4 $\left.4_{1-328}\right)$. As revealed by LC-MS/MS, UBA4 $4_{1-328}$ cells still allowed for residual tRNA thiolation in the absence of Tum1 (Fig. 5B). Importantly, the remaining low $\mathrm{mcm}^{5} \mathrm{~s}^{2} \mathrm{U} 34$ levels ( $\sim \%$ in relation to UBA4 wild-type) were similar, if not identical in both TUM1 and tum $1 \triangle$ cells (Fig. 5B). To support this result, which points towards residual tRNA thiolation independent of TUM1, we investigated whether an additional tum $1 \Delta$ null-allele affects the partial suppression of elp $3 \Delta u b a 4 \Delta$ or deg $1 \Delta u b a 4 \Delta$ growth by $U B A 4_{1-328}$ (Fig. S6). If Tum1 accounted for residual activity of Uba4 $4_{1}$ 328, partial suppression may be abolished by TUM1 gene deletion. However, the phenotypic assays clearly demonstrate the opposite: a tum $1 \Delta$ null-allele has no effect on partial suppression of elp $3 \Delta u b a 4 \Delta$ or $\operatorname{deg} 1 \Delta u b a 4 \Delta$ cell growth by $U B A 4_{1-328}$ (Fig. S6). Similarly, weak protein urmylation typical of $U B A 4_{1-328}$ cells was not altered in tandem with tum1 1 (Fig. 5D) indicating no additive effect of reduced S-transfer onto residual performance of Uba4 $4_{1-328}$. This shows low residual levels of tRNA thiolation and urmylation in the absence of RHD are insensitive to Tum1, suggesting that Tum1-dependent S-transfer for proper function of Uba4 operates mainly, if not entirely, through its $\mathrm{RHD}$ region.

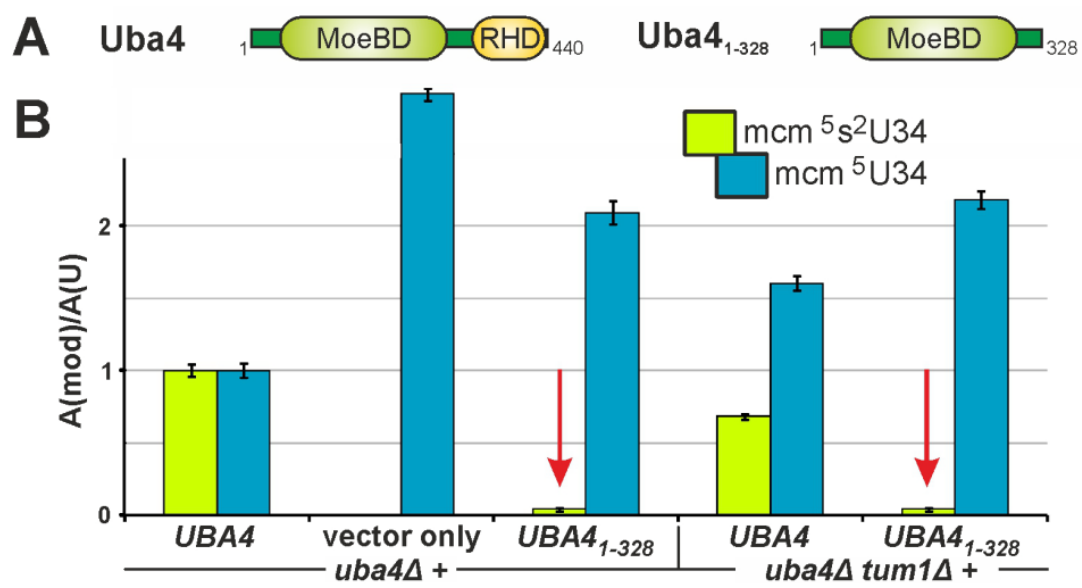

C

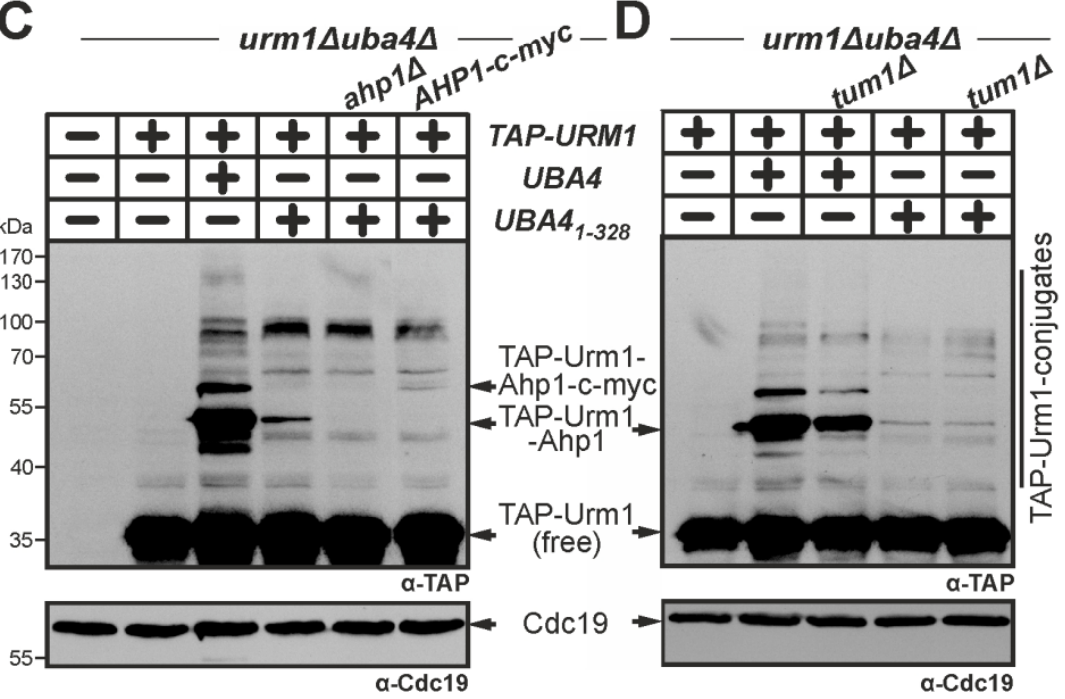

FIGURE 5: Low residual tRNA thiolation and urmylation without the RHD on Uba4 is independent of sulfur transfer by Tum1. (A) Scheme depicting Uba41-328, which lacks the RHD region. (B) LC-MS/MS-based analysis (see Fig. 3) reveals Uba4 ${ }_{1-328}$ is severely compromised in tRNA thiolation (red arrows) with the remaining residual $(\sim 4 \%)$ levels of $\mathrm{mcm}^{5} \mathrm{~s}^{2}$-modified U34 insensitive to TUM1 gene function. (C, D) Urmylation of proteins including Ahp1 is strongly suppressed in the absence of the RHD. Urmylation assays on protein extracts from the indicated genetic backgrounds involved anti-TAP-based EMSA (see Fig. 2) and immune blots to detect nonconjugated (free) TAP-Urm1 and TAP-Urm1 conjugates $(C, D)$ including urmylated forms of wild-type (C, D) and c-myc-tagged Ahp1 (D). Protein loading (C, D) was controlled with antiCdc19 Western blots. Note that as is the case with very weak Tum1 insensitive tRNA thiolation (B), low residual levels of urmylation with Uba4 $_{1-328}$ are also unaltered in the tum $1 \Delta \mathrm{mu}$ tant (D). 


\section{DISCUSSION}

Compared to ubiquitin and ubiquitin-like proteins, Urm1 activation differs by thiocarboxylation $[18,19]$. Urm1-COSH generated this way provides sulfur for tRNA thiolation (Fig. 1 ) and possibly protein urmylation $[6,18,23]$. Such shared need for Urm1-COSH suggests both Urm1 functions are linked. Hence, we reasoned that conditions inactivating tRNA thiolation [36, 38-41] may also impact on urmylation. We show herein that cells grown at $39^{\circ} \mathrm{C}$ or starved for sulfur drastically suppress urmylation. At $39^{\circ} \mathrm{C}$, loss of urmylation correlated with decreased levels of Urm1 itself, while S-starvation had no such effect (Fig. 2). This goes along with other URM1 pathway proteins (Tum1, Uba4, Ncs2, Ncs6) also reported to be unstable at higher temperatures $[36,39]$. While instable thiolase $(\mathrm{Ncs} 2 \bullet N \operatorname{cs} 6)$ affects tRNA thiolation, lowering Tum1 and Uba4 activities will interfere with S-transfer and Urm1 activation. So, suppression of urmylation at $39^{\circ} \mathrm{C}$ may be due to fragile Urm1 alone or combined with improper Urm1 activation [18, 19]. URM1 pathway inactivation in S-starved cells (Fig. 3) is readily explained by the need of sulfur for Urm1-COSH formation $[6,18,23]$. In sum, suppression of tRNA thiolation and urmylation at $39^{\circ} \mathrm{C}$ or upon S-depletion likely involves inappropriate Urm1 thiocarboxylation.

Down-regulation of tRNA thiolation was suggested to reduce translational competence and cell growth under sulfur limiting conditions which may be important to spare sulfur for other physiologically important processes [38]. Since we show Urm1 conjugation depends on Urm1-COSH and hence qualifies itself as a sulfur consuming process, loss of urmylation upon S-depletion could help spare sulfur as well. Also, we cannot exclude that a decrease in urmylation affects the activity of protein(s) that Urm1 attaches to.
Probably, this may help to adapt to conditions known to be URM1 pathway related, i.e. ROS, thermo-stress, Sdepletion $[6,11,17,38-41]$. However, with attachment of ubiquitin-like modifiers such as SUMO regulating the activity of their targets in ways different from Urm1 [2, 48-50], how precisely urmylation impacts on its targets is still not clear.

Our findings that it is the activated sulfur in Urm1COSH, which links tRNA thiolation and urmylation, may provide support for a previous model [37] that sees urmylation as a means to restrict - rather than spare (see above) - sulfur flow by reducing the pool of free Urm1 available for S-transfer and tRNA thiolation. Consistent with this, Elongator mutants with URM1 pathway related $\mathrm{mcm}^{5} \mathrm{~s}^{2} \mathrm{U} 34$ modification defects (Fig. 1) allow urmylation to occur [5] and our data show thiolase mutants (ncs2 $\Delta$, $n \operatorname{cs} 6 \Delta$ ) maintain wild-type levels of Ahp1 urmylation (Fig. 3). To check if this relationship is reciprocal we asked whether tRNA thiolation is affected by loss of Ahp1 urmylation and profiled yeast growth inhibition by a fungal tRNase (zymocin) (Fig. 6A, B) that requires $\mathrm{mcm}^{5} \mathrm{~s}^{2}$-modified U34 for lethal anticodon cleavage $[28,51,52]$. While strains with defects in S-transfer (tum1 $\Delta$ ) and tRNA thiolation (urm1 $\Delta$, $n c s 6 \Delta$ ) protected against zymocin (Fig. $6 C, D$ ) loss of Ahp1 urmylation (ahp1 $\Delta$ ) could not. This indicates lethal anticodon cleavage due to proper tRNA thiolation occurs in the absence of Ahp1 urmylation. Together with our findings above, that tRNA thiolation is not required for Ahp1 urmylation, the two URM1 pathway branches - albeit mechanistically linked through sulfur activation - seem to be functionally separated from (rather than dependent on) each other. So to our minds, an above scenario where sulfur flow for tRNA thiolation is kept in-check by Ahp1
A

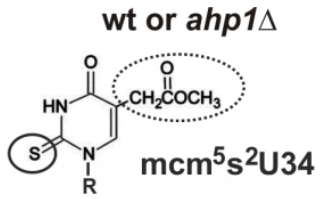

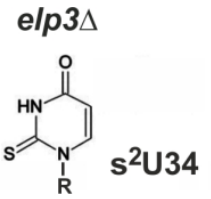

tum $1 \Delta$, urm $1 \Delta$ or $n c s 6 \Delta$

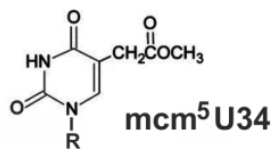

B
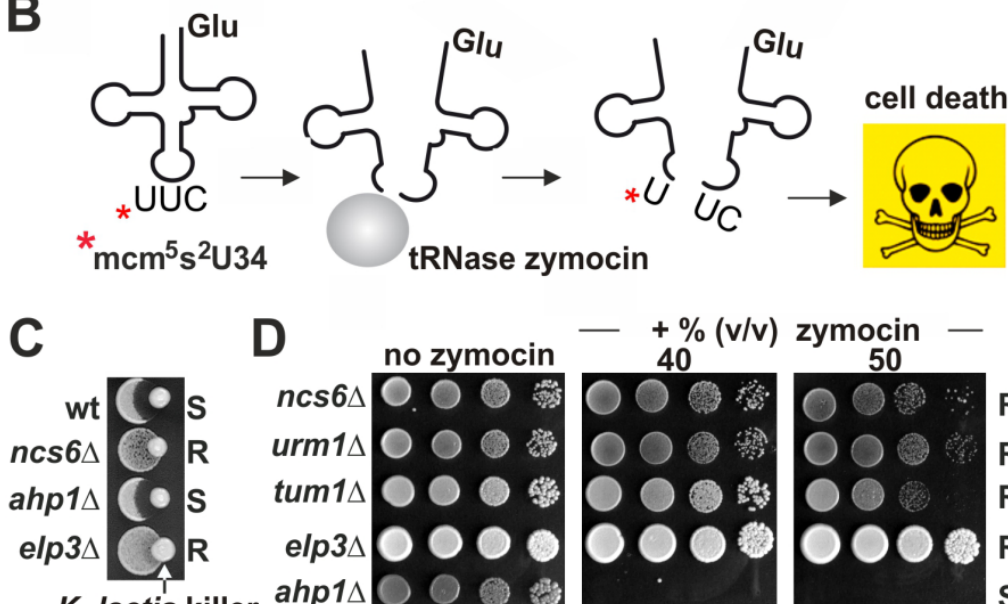

K. lactis killer

no zymocin
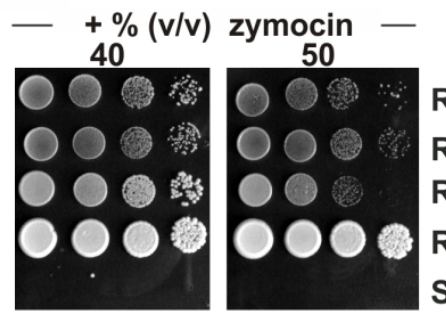

(zymocin producer)

ten-fold serial cell dilutions

FIGURE 6: The role of Urm1 in tRNA thiolation, not in urmylation of Ahp1, drives tRNase toxicity. (A) Shown are wobble uridine (U34) modifications from different genetic backgrounds: 5methoxycarbonyl-methyl-2-thiouridine $\left(\mathrm{mcm}^{5} \mathrm{~s}^{2} \mathrm{U}\right.$ $34)$, thiouridine ( $\left.\mathrm{s}^{2} \cup 34\right)$ and 5-methoxycarbonylmethyl-uridine $\left(\mathrm{mcm}^{5} \mathrm{U} 34\right)$. For simplicity, ' $R$ ' denotes ribose moieties. U34 thiolation (solid circle) requires S-transfer via Tum1, Urm1・Uba4 and thiolase Ncs2•Ncs6; $\mathrm{mcm}^{5}$ side-chain (dotted circle) formation depends on Elongator [24, 28]. (B) The $\mathrm{mcm}^{5} \mathrm{~s}^{2} \mathrm{U} 34$ modification (asterisk) in tRNA ${ }^{\text {Glu }}{ }^{*} \cup \mathrm{c}$ is efficiently cleaved by zymocin, a fungal tRNase lethal to $S$. cerevisiae cells (see C) $[28,56,57]$. (C, D) U34 modification defects (elp $3 \Delta$, tum $1 \Delta$, urm $1 \Delta, n c s 6 \Delta$ ) protect against zymocin and loss of Ahp1 urmylation (ahp1A) confers wildtype (wt) like sensitivity. Growth tests involved killer eclipse assays using $K$. lactis zymocin producer and the indicated $S$. cerevisiae tester strains (see C) or toxin plate assays with ten-fold serial dilutions of the indicated tester strains in absence (left panel) or presence (other panels) of different doses of zymocin purified from $K$. lactis (see D). 'S' and ' $R$ ' indicate toxin sensitive and resistant responses, respectively. 
urmylation seems unlikely. We cannot, however, exclude targets other than Ahp1 whose urmylation still may affect tRNA thiolation. In this context, it is noteworthy that hURM1 and Urm1-like proteins (SAMP, TtuB) form conjugates with human and prokaryal orthologs of yeast thiolase (CTU2, ATPBD3, NcsA, TtuA) [6, 12, 13]. Whether this implies that S-transfer (via Urm1-COSH) for tRNA thiolation involves urmylation of components of the thiolase is unknown but may be an attractive twist to the above topic as it suggests the option of interdependence among the two URM1 pathway branches. Although the Sdonor role for tRNA thiolation has been demonstrated in vitro using human URM1 pathway players including hURM1 and CTU2 [23], we are not aware of sulfur transfer during lysine-directed urmylation to targets that Urm1 attaches to in yeast or other organisms.

In support of our findings that tRNA thiolation and urmylation depend on sulfur (Fig. 3), both URM1 pathway branches are significantly impaired in the absence of sulfur transferase Tum1. Interestingly, Tum1 seems not to contribute to urmylation of Uba4 suggesting this conjugation does not rely on S-transfer via Tum1 for Urm1-COSH formation (Fig. S4). Instead, an alternative mechanism, more similar to E1-like activation of ubiquitin-like modifiers, may be envisaged involving thioester bond formation prior to lysine-directed urmylation [21]. Remarkably, SUMO, a ubiquitin-like modifier, SUMOylates the Uba2 subunit of its own E1 complex at Lys residue 236 and without any E2 assistance [53]. Since E2/E3 urmylation enzymes are elusive, Uba4•Urm1 auto-urmylation comparable to Uba2-SUMO auto-SUMOylation may be plausible. Indeed, using site-directed UBA4 mutagenesis, we identified Lys candidate residues $(\mathrm{K} 122, \mathrm{~K} 248)$ that differentially contribute to Uba4 or Ahp1 urmylation (Fig. S8).

In contrast to previous reports $[3,9,18]$, we demonstrate here that Cys residues in the MoeBD (C225) and RHD (C397) domains of Uba4 are catalytically important for formation of Urm1-COSH yet not essential (Fig. 4). This is based on our findings that mimetic Ser substitutions alone or combined (C225S, C397S, C225S/C397S) cannot entirely abolish Uba4 functions but progressively reduce tRNA thiolation and urmylation to levels (14-25\%) sufficient enough to form significant amounts of Urm1 conjugates and $s^{2} U 34-$ modifed tRNA anticodons (Fig. 4). While it was shown that C397 can be persulfurated, which results in acyl-disulfide bond formation with Urm 1 and subsequently in the release of Urm1-COSH $[8,9,18,23]$, the role of C225 is unclear. C225 is analogous to active-site Cys residues in ubiquitinlike E1 enzymes but we are not aware it forms a thioester bond with Urm1 in vivo. Moreover, it is not essential for in vitro adenylation or thiocarboxylation of human URM1 by MOCS3/hUBA4 [18]. Hence, a potential role for C225 in the reductive cleavage of the acyl-disulfide bond between MOCS3 and hURM1 was proposed [18]. Our data showing residual sulfur transfer with $\mathrm{C} 225 \mathrm{~S}$ alone or combined with C397S (Fig. 4) may indicate the presence of another Cys residue capable of reductive cleavage and Urm1-COSH release. An alternative cysteine present in Uba4 or provided by yet another protein might also explain why the
C397S mutant allowed, albeit at significantly reduced efficiencies, S-transfer for tRNA thiolation and urmylation (Fig. 4). Residual low-level tRNA thiolation and urmylation are even more compromised with $\mathrm{Uba}_{1-328}$, the truncation lacking the RHD (including C397) and importantly, uncoupled from Tum1 (Fig. 5). This suggests an alternative sulfur mode of transfer which either involves a Cys residue other than C225 in the MoeBD motif of Uba4 or an S-donor distinct from Tum1 (Fig. S9). The latter (if existent) may be identified among candidates with assigned or cryptic RHDs of the rhodanese protein family [54, 55].

\section{MATERIALS AND METHODS}

Yeast strains, general methods and plasmid constructions Growth of yeast strains (Table S1) was in routine YPD or SC media [56] for 3 days, and thermosensitivity was assayed on YPD media at $34^{\circ} \mathrm{C}, 35^{\circ} \mathrm{C}$ or $39^{\circ} \mathrm{C}$. Table S2 lists primers used for PCR-based protocols $[57,58]$ to introduce site-specific UBA4 mutations or generate and diagnose gene deletions. Uba4 cysteine to serine substitutions C225S, C397S and C225S/C397S carried on plasmids pAJ64, pAJ65 and pAJ69, respectively (Table S3) were generated by PCR-based sitedirected mutagenesis using a previously described protocol [59]. Correctness of each mutation was confirmed by Sangerbased DNA sequencing. In analogy, site-directed UBA4 mutagenesis of lysine residues (K122, K132, K156, K248) in the MoeBD of Uba4 resulted in arginine substitutions (Table S2). For UBA4 $4_{1-328}$ expression in yeast, the ORF coding for the $\mathrm{N}$ terminal MoeB-like domain (MoeBD) of Uba4 alone was PCRamplified from template plasmid pAJ16 [11]. Using flanking Notl and Ndel restriction sites, the UBA4 ${ }_{1-328}$-construct was then cloned into vector pAJ16, resulting in generation of pAJ82 (Table S3). Construction of plasmid pAJ113 (Table S3) for expression of the rhodanese-type domain (RHD) of Uba4 alone started with PCR-amplification of the UBA4 $329-440^{-} \mathrm{T}_{\mathrm{CYC1}^{-}}$ fragment from template plasmid pAJ16 [11]. This fragment was subcloned into $\mathrm{Ndel}$ - and Sacl-digested plasmid pAJ16, giving rise to a $U B A 4_{329-440^{-}} T_{C Y C 1}$-fragment, which was finally moved to yeast single copy vector pRS423 [60] restricted with BamHI and Sacl. Transformation of yeast cells with PCR products or plasmids (Table S3) was done as previously described [61]. Qualitative assays to monitor sensitivity or resistance of $S$. cerevisiae cells to growth inhibition by the zymocin tRNase toxin complex involved previously described killer eclipse bioassays [33]. In more sensitive assays, growth performance of ten-fold serial dilutions of $S$. cerevisiae tester strains was monitored for $2-3$ days at $30^{\circ} \mathrm{C}$ on YPD plates containing no toxin or $40-50 \%(\mathrm{v} / \mathrm{v})$ partially purified zymocin [33]. Both assays used $K$. lactis killer strain AWJ137 (Table S1) as zymocin producer.

\section{tRNA modification profiling}

Total tRNA was isolated from yeast cultures and subjected to LC-MS/MS for tRNA anticodon modification analysis essentially as previously described [26, 35, 62]. Identification of mcm $\mathrm{m}^{5} 4$ or $\mathrm{mcm}^{5} \mathrm{~s}^{2} \mathrm{U} 34$ peaks was according to Jüdes et al. [11]. For intersample comparability of the detected modifications, the peak areas of the modified nucleosides, measured in triplicates, were normalized to the UV peak area of uridine. 


\section{Urmylation studies using electrophoretic mobility shift assays (EMSA)}

Urmylation studies were done essentially as described [11] with yeast grown in standard $\mathrm{SC}$ media at $30^{\circ} \mathrm{C}$ to an $\mathrm{OD}_{600}$ of 1.0 [56]. To analyze whether Urm1 conjugation is affected by elevated temperatures, logarithmically growing yeast cells were shifted from $30^{\circ} \mathrm{C}$ to $39^{\circ} \mathrm{C}$ and sampled after 1-3 hours of incubation at $39^{\circ} \mathrm{C}$. To monitor sulfur dependency of urmylation, methionine auxotrophic (met15 $\Delta$ ) cells in the background of BY4741 (Table S1) were pregrown to logarithmic growth phase in standard SC minimal media [56] containing the sulfur amino acid methionine $(2 \mathrm{mg} / \mathrm{ml})$, washed and further suspended in SC media without methionine as a sulfur source. Finally, cells were harvested after 1 and 2 hours of additional cultivation and broken open with a bead beater and lysed in a buffer (10 mM K-HEPES pH 7.0, $10 \mathrm{mM} \mathrm{KCl}, 1.5 \mathrm{mM} \mathrm{MgCl}, 0.5$ $\mathrm{mM}$ PMSF, $2 \mathrm{mM}$ benzamidine) containing complete protease inhibitors (Roche) and $10 \mathrm{mM} \mathrm{N}$-ethylmaleimide (NEM) as previously described $[6,11]$. EMSA and Western blot analyses used PVDF membranes essentially as described [11]. Detection of unconjugated Ahp1 in NEM-free samples used anti-Ahp1 serum [63] provided by Dr Kuge (Tohoku Pharmaceutical University, Japan). Protein loading was checked using antiCdc19 antibodies donated by $\mathrm{Dr}$ Thorner (University of California, USA).

\section{ACKNOWLEDGMENTS}

We thank Katrin L. Thüring (Universität Mainz, Germany) for technical assistance with the LC-MS/MS profiles and Dr Christian Bär (Medizinische Hochschule Hannover, Germany) for Uba4•Urm1 pioneering work. Drs Kuge (Tohoku Pharmaceutical University, Japan), Thorner (University of
California, USA) and Ohsumi (Tokyo Institute of Technology, Japan) kindly provided anti-Ahp1 \& anti-Cdc19 antibodies and the HA-Urm1 expression plasmid. We thank Drs Leimkühler (University of Potsdam, Germany) and Stark (University of Dundee, Scotland, UK) for reading the manuscript. Project support by DFG and funds through their Priority Program 1784 Chemical Biology of Native Nucleic Acid Modifications to RK (KL 2937/1), MH (HE 3397/13) and RS (SCHA 750/15 \& 750/20) are gratefully acknowledged.

\section{SUPPLEMENTAL MATERIAL}

All supplemental data for this article are available online at www.microbialcell.com.

\section{CONFLICT OF INTEREST}

The authors declare there is no conflict of interest.

\section{COPYRIGHT}

(C) 2016 Jüdes et al. This is an open-access article released under the terms of the Creative Commons Attribution (CC BY) license, which allows the unrestricted use, distribution, and reproduction in any medium, provided the original author and source are acknowledged.

Please cite this article as: André Jüdes, Alexander Bruch, Roland Klassen, Mark Helm and Raffael Schaffrath (2016). Sulfur transfer and activation by ubiquitin-like modifier system Uba4•Urm 1 link protein urmylation and tRNA thiolation in yeast. Microbial Cell 3(11): 554-564. doi: 10.15698/mic2016.11.539

9. Noma A, Sakaguchi Y, and Suzuki T (2009). Mechanistic characterization of the sulfur-relay system for eukaryotic 2-thiouridine biogenesis at tRNA wobble positions. Nucleic Acids Res 37(4): 1335-1352.

10. Nakai Y, Harada A, Hashiguchi Y, Nakai M, and Hayashi H (2012). Arabidopsis molybdopterin biosynthesis protein $\mathrm{Cnx5}$ collaborates with the ubiquitin-like protein Urm11 in the thio-modification of tRNA. J Biol Chem 287(36): 30874-30884.

11. Jüdes $A$, Ebert $F$, Bär $C$, Thüring $K L$, Harrer $A$, Klassen $R$, Helm $M$, Stark MJ, and Schaffrath R (2015). Urmylation and tRNA thiolation functions of ubiquitin-like Uba4-Urm1 systems are conserved from yeast to man. FEBS Lett 589(8): 904-909.

12. Shigi N (2012). Posttranslational modification of cellular proteins by a ubiquitin-like protein in bacteria. J Biol Chem 287(21): 1756817577.

13. Maupin-Furlow JA (2014). Prokaryotic ubiquitin-like protein modification. Annu Rev Microbiol 68: 155-175.

14. Fichtner L, Jablonowski D, Schierhorn A, Kitamoto HK, Stark MJ, and Schaffrath $R$ (2003). Elongator's toxin-target (TOT) function is nuclear localization sequence dependent and suppressed by posttranslational modification. Mol Microbiol 49(5): 1297-1307.

15. Scheidt V, Jüdes A, Bär C, Klassen R, and Schaffrath R (2014). Loss of wobble uridine modification in tRNA anticodons interferes with TOR pathway signaling. Microb Cell 1(12): 416-424. 
16. Zinshteyn B and Gilbert WV (2013). Loss of a conserved tRNA anticodon modification perturbs cellular signaling. PLoS Genet 9(8): e1003675.

17. Khoshnood B, Dacklin I, and Grabbe C (2016). Urm1: an essential regulator of JNK and oxidative stress in Drosophila melanogaster. Cell Mol Life Sci 73(9): 1939-1954.

18. Schmitz J, Chowdhury MM, Hänzelmann $P$, Nimtz $M$, Lee $E Y$, Schindelin $H$, and Leimkühler S (2008). The sulfurtransferase activity of Uba4 presents a link between ubiquitin-like protein conjugation and activation of sulfur carrier proteins. Biochemistry 47(24): 6479-6489.

19. Pedrioli PG, Leidel S, and_Hofmann K (2008). Urm1 at the crossroad of modifications. Protein modifications: beyond the usual suspects - Review Series. EMBO Rep 9(12): 1196-1202.

20. Lake MW, Wuebbens MM, Rajagopalan KV, and Schindelin H (2001). Mechanism of ubiquitin activation revealed by the structure of a bacterial MoeB-MoaD complex. Nature 414(6861): 325-329.

21. Burroughs $A M$, lyer $L M$, and Aravind $L$ (2009). Natural history of the E1-like superfamily:Implication for adenylation, sulfur transfer and ubiquitin conjugation. Proteins 75(4): 895-910.

22. Marelja Z, Stöcklein W, Nimtz M, and Leimkühler S. (2008) A novel role for human $\mathrm{Nfs} 1$ in the cytoplasm: $\mathrm{Nfs} 1$ acts as a sulfur donor for MOCS3, a protein involved in molybdenum cofactor biosynthesis. J Biol Chem 283(37): 25178-25185.

23. Chowdhury MM, Dosche C, Löhmannsröben HG, and Leimkühler S (2012). Dual role of the molybdenum cofactor biosynthesis protein MOCS3 in tRNA thiolation and molybdenum cofactor biosynthesis in humans. J Biol Chem 287(21): 17297-17307.

24. Huang B, Johansson MJ, and Byström AS (2005). An early step in wobble uridine tRNA modification requires the Elongator complex. RNA 11(4): 424-436

25. Björk GR, Huang B, Persson OP, and Byström AS (2007). A conserved modified wobble nucleoside ( $\mathrm{mcm} 5 \mathrm{~s} 2 \mathrm{U})$ in lysyl-tRNA is required for viability in yeast. RNA 13(8): 1245-1255.

26. Mehlgarten C, Jablonowski D, Wrackmeyer U, Tschitschmann S, Sondermann D, Jäger G, Gong Z, Byström AS, Schaffrath R, and Breunig KD (2010). Elongator function in tRNA wobble uridine modification is conserved between yeast and plants. Mol Microbiol 76(5): 1082-1094.

27. Johansson MJ, Esberg A, Huang B, Björk GR, and Byström AS (2008). Eukaryotic wobble uridine modifications promote a functionally redundant decoding system. Mol Cell Biol 28(10): 3301-3312.

28. Jablonowski D, Zink S, Mehlgarten $C$, Daum G, and Schaffrath $R$ (2006). tRNA ${ }^{\text {Glu }}$ wobble uridine methylation by Trm9 identifies Elongator's key role for zymocin-induced cell death in yeast. Mol Microbiol 59(2): 677-688.

29. Tükenmez H., Xu H, Esberg A, and Byström AS (2015). The role of wobble uridine modifications in +1 translational frameshifting in eukaryotes. Nucleic Acids Res 43(19): 9489-9499.

30. Nedialkova DD and Leidel SA (2015). Optimization of codon translation rates via tRNA modifications maintains proteome integrity. Cell 161(7): 1606-1618.

31. Chan CT, Dyavaiah M, DeMott MS, Taghizadeh K, Dedon PC, and Begley TJ (2010). A quantitative systems approach reveals dynamic control of tRNA modifications during cellular stress. PLoS Genet 6(12): e1001247.

32. Su D, Chan CT, Gu C, Lim KS, Chionh YH, McBee ME, Russell BS, Babu IR, BegleyTJ, and Dedon PC (2014). Quantitative analysis of ribonucleoside modifications in tRNA by HPLC-coupled mass spectrometry. Nat Protoc 9(4): 828-841.
33. Jablonowski D, Fichtner L, Stark MJ, and Schaffrath R (2004). The yeast Elongator histone acetylase requires Sit4-dependent dephosphorylation for toxin-target capacity. Mol Biol Cell 15(3): 14591469.

34. Mehlgarten $C$, Jablonowski D, Breunig KD, Stark MJ, and Schaffrath $R$ (2009). Elongator function depends on antagonistic regulation by casein kinase Hrr25 and protein phosphatase Sit4. Mol Microbiol 73(5): 869-881.

35. Abdel-Fattah W, Jablonowski D, Di Santo R, Thüring KL, Scheidt V, Hammermeister A, Ten Have S, Helm M, Schaffrath R, and Stark MJ (2015). Phosphorylation of Elp1 by Hrr25 is required for Elongatordependent tRNA modification in yeast. PLoS Genet 11(1): e1004931.

36. Damon JR, Pincus D, and Ploegh HL (2015). tRNA thiolation links translation to stress responses in Saccharomyces cerevisiae. Mol Biol Cell 26(2): 270-282.

37. Petroski MD, Salvesen GS, and Wolf DA (2011). Urm1 couples sulfur transfer to ubiquitin-like protein function in oxidative stress. Proc Natl Acad Sci USA 108(5): 1749-1750.

38. Laxman S, Sutter BM, Wu X, Kumar S, Guo X, Trudgian DC, Mirzaei $H$, and Tu BP (2013). Sulfur amino acids regulate translational capacity and metabolic homeostasis through modulation of tRNA thiolation. Cell 154(2): 416-429.

39. Tyagi K and Pedrioli PG (2015). Protein degradation and dynamic tRNA thiolation fine-tune translation at elevated temperatures. Nucleic Acids Res 43(9): 4701-4712.

40. Alings F, Sarin LP, Fufezan C, Drexler HC, and Leidel SA (2015). An evolutionary approach uncovers a diverse response of tRNA 2thiolation to elevated temperatures in yeast. RNA 21(2): 202-212.

41. Han L, Kon $Y$, and Phizicky EM (2015). Functional importance of $\Psi 38$ and $\Psi 39$ in distinct tRNAs, amplified for tRNAGIn(UUG) by unexpected temperature sensitivity of the $\mathrm{s} 2 \mathrm{U}$ modification in yeast. RNA 21(2): 188-201.

42. Rezgui VA, Tyagi K, Ranjan N, Konevega AL, Mittelstaet J, Rodnina MV, Peter M, and Pedrioli PG (2013). tRNA tKUUU, tQUUG, and tEUUC wobble position modifications fine-tune protein translation by promoting ribosome A-site binding. Proc Natl Acad Sci USA 110(30): 12289-12294.

43. Klassen $R$, Grunewald $P$, Thüring $K L$, Eichler $C$, Helm $M$, and Schaffrath $R$ (2015). Loss of anticodon wobble uridine modifications affects tRNA ${ }^{\text {Lys }}$ function and protein levels in Saccharomyces cerevisiae. PLOS ONE 10(3): e0119261.

44. Klassen R, Ciftci A, Johanna Funk J, Bruch A, Butter F, and Schaffrath $R$ (2016). tRNA anticodon loop modifications ensure protein homeostasis and cell morphogenesis in yeast. Nucleic Acids Res pii: gkw705 [Epub ahead of print]

45. Fräsdorf B, Radon C, and Leimkühler S (2014). Characterization and interaction studies of two isoforms of the dual localized 3mercaptopyruvate sulfurtransferase TUM1 from humans. J Biol Chem 289(50): 34543-34556.

46. Selvadurai K, Wang $P$, Seimetz J, and Huang RH (2014). Archaeal Elp3 catalyzes tRNA wobble uridine modification at $\mathrm{C} 5$ via a radical mechanism. Nat Chem Biol 10(10): 810-812.

47. Lecointe F, Simos G, Sauer A, Hurt EC, Motorin Y, and Grosjean H (1998). Characterization of yeast protein Deg1 as pseudouridine synthase (Pus3) catalyzing the formation of psi 38 and psi 39 in tRNA anticodon loop. J Biol Chem 273(3): 1316-1323.

48. Palacios S, Perez LH, Welsch S, Schleich S, Chmielarska K, Melchior F, and Locker JK (2005). Quantitative SUMO-1 modification of a vaccinia virus protein is required for its specific localization and prevents its self-association. Mol Biol Cell 16(6): 2822-2835. 
49. Steinacher R and Schär P (2005). Functionality of human thymine DNA glycosylase requires SUMO-regulated changes in protein conformation. Curr Biol 15(7): 616-623.

50. Husnjak K, Elsasser S, Zhang N, Chen X, Randles L, Shi Y, Hofmann $\mathrm{K}$, Walters KJ, Finley D, and Dikic I (2008). Proteasome subunit Rpn13 is a novel ubiquitin receptor. Nature 453(7194): 481-488.

51. Lu J, Huang B, Esberg A, Johansson MJ, and Byström AS (2005). The Kluyveromyces lactis gamma-toxin targets tRNA anticodons. RNA 11(11): 1648-1654.

52. Jablonowski D and Schaffrath R (2007). Zymocin, a composite chitinase and tRNase killer toxin from yeast. Biochem Soc Trans 35(6): 1533-1537.

53. Truong K, Lee TD, and Chen Y (2012). Small ubiquitin-like modifier (SUMO) modification of E1 Cys domain inhibits E1 Cys domain enzymatic activity. J Biol Chem 287(19): 15154-15163.

54. Hofmann K, Bucher P, and Kajava AV (1998). A model of Cdc25 phosphatase catalytic domain and Cdk-interaction surface based on the presence of a rhodanese homology domain. J Mol Biol 282(1): 195-208.

55. Bordo D and Bork P (2002). The rhodanese/Cdc25 phosphatase superfamily. Sequence-structure-function relations. EMBO Rep 3(8): 741-746.

56. Sherman F (1991). Guide to yeast genetics and molecular biology. Getting started with yeast. Methods Enzymol 194: 3-20.
57. Knop M, Siegers K, Pereira G, Zachariae W, Winsor B, Nasmyth K, and Schiebel E (1999). Epitope tagging of yeast genes using a PCRbased strategy: more tags and improved practical routines. Yeast 15(10B): 963-972.

58. Gueldener U, Heinisch J, Koehler GJ, Voss D, and Hegemann JH (2002). A second set of loxP marker cassettes for Cre-mediated multiple gene knockouts in budding yeast. Nucleic Acids Res 30(6): e23.

59. Wang W and Malcolm BA (1999) Two-stage PCR protocol allowing introduction of multiple mutations, deletions and insertions using QuikChange site-directed mutagenesis. Biotechniques 26(4): 680-682.

60. Christianson TW, Sikorski RS, Dante M, Shero JH, and Hieter $P$ (1992). Multifunctional yeast high-copy-number shuttle vectors. Gene 110(1): 119-122.

61. Gietz RD and Woods RA (2002). Transformation of yeast by lithium acetate/single-stranded carrier DNA/polyethylene glycol method. Methods Enzymol 350: 87-96.

62. Kellner S, Neumann J, Rosenkranz D, Lebedeva S, Ketting RF., Zischler $\mathrm{H}$, Schneider D, and Helm M (2014). Profiling of RNA modifications by multiplexed stable isotope labelling. Chem Commun 50(26): 3516-3518.

63. Iwai K, Naganuma A, and Kuge S (2010). Peroxiredoxin Ahp1 acts as a receptor for alkylhydroperoxides to induce disulfide bond formation in the Cad1 transcription factor. J Biol Chem 285(14): 1059710604. 